\title{
Anabases
}

ANABASES Traditions et réceptions de l'Antiquité

$15 \mid 2012$

Varia

\section{Françoise FRAZIER et Delphim F. LEAO (éd.), Tychè et Pronoia. La marche du monde selon Plutarque}

\section{Germaine Aujac}

\section{OpenEdition}

Journals

Édition électronique

URL : http://journals.openedition.org/anabases/3830

DOI : 10.4000/anabases.3830

ISSN : 2256-9421

\section{Éditeur}

E.R.A.S.M.E.

\section{Édition imprimée}

Date de publication : 1 avril 2012

Pagination : 266

ISSN : 1774-4296

\section{Référence électronique}

Germaine Aujac, « Françoise frazier et Delphim f. Leao (éd.), Tychè et Pronoia. La marche du monde selon Plutarque », Anabases [En ligne], 15 | 2012, mis en ligne le 01 avril 2012, consulté le 22 septembre 2020. URL : http://journals.openedition.org/anabases/3830 ; DOI : https://doi.org/10.4000/anabases. 3830

Ce document a été généré automatiquement le 22 septembre 2020

(c) Anabases 


\title{
Françoise FRAZIER et Delphim F. LEAO (éd.), Tychè et Pronoia. La marche du monde selon Plutarque
}

\author{
Germaine Aujac
}

\section{RÉFÉRENCE}

Françoise FRAZIER et Delphim F. LEAO (éd.), Tychè et Pronoia. La marche du monde selon Plutarque, Coimbra, Classica Digitalia, 2010, $268 \mathrm{p}$.

29 euros / ISBN : 978-989-8281-52-4, ISBN Digital : 978-989-8281-53-1.

1 Comme il est indiqué dans la préface, et repris sur la quatrième de couverture, «le présent volume trouve son origine dans la rencontre annuelle du Réseau international de recherche et de formation à la recherche Plutarque (RED) qui s'est tenue à la Maison de l'archéologie et de l'ethnologie René-Ginouvès de Nanterre en novembre 2009 ». Le thème original, qui portait sur "Hasard, fortune, providence ", a été légèrement modifié pour la publication des actes afin de mieux mettre en lumière «la spécificité des notions grecques ici examinées, spécificité qui intéresse le philosophe comme le philologue».

2 Après une introduction par Fr. Frazier qui souligne les incertitudes de la Tyché en œuvre dans la marche du monde (p. III-XXIII), les quinze communications sont regroupées sous trois axes: Doctrines et débats philosophiques; Les relations des hommes et des dieux ; Interprétations de l'action humaine.

Les « Doctrines et débats philosophiques » ont réuni Espagnols et Italiens. Rosa Maria Aguilar, de Madrid, s'intéresse à la vision du monde présentée par Thespesios et par Timarque dans les mythes de deux Moralia: le De sera numinis vindicta et le De Genio Socratis (p. 3-12). Raul Caballero, de Malaga, s'appuyant sur le chap. 23 des Contradictions des stoïciens, montre les ressorts de la polémique qui opposait le stoïcien Ariston de Chios à l'académicien Arcésilas (p. 13-33); il ajoute en appendice (p. 34-37) le texte de 
Plutarque, sa traduction par l'A., un extrait du De finibus de Cicéron, un extrait de Diogène Laerce évoquant cette querelle, un autre de l'Adversus Colotem, un de Galien et un de Sextus Empiricus, ce qui illustre à merveille l'important retentissement de cette discussion sur la liberté d'indifférence. Paola Volpe Cacciatore, de Salerne, dans son exposé « Fato e Fortuna negli opuscoli contro gli Stoici di Plutarco, un problema ancora aperto » (p. 39-46), montre que Plutarque tente d'établir un équilibre dans les relations entre la Providence et la liberté d'action de l'homme. Francesco Becchi, de Florence, étudie l'écrit de Plutarque Sur la Fortune.

\section{AUTEURS}

\section{GERMAINE AUJAC}

Université de Toulouse (UTM) aujac.germaine@wanadoo.fr 